\title{
Reuso de resíduo de lama de papel na produção de suporte cerâmico poroso de baixo custo
}

\section{(Reuse of paper sludge waste in the production of low-cost porous ceramic support)}

\author{
R. A. Bou-Issa', R. L. Loiola ${ }^{1}$, J. N. F. Holanda ${ }^{1 *}$ \\ ${ }^{I}$ Universidade Estadual do Norte Fluminense Darcy Ribeiro, LAMAV-CCT, Grupo de Materiais Cerâmicos, Av. \\ Alberto Lamego 2000, 28013-602, Campos dos Goytacazes, RJ, Brasil
}

\begin{abstract}
Resumo
A indústria de papel gera enorme volume de resíduo de lama de papel. Neste trabalho foi desenvolvido um novo suporte cerâmico poroso usando resíduo de lama de papel como matéria-prima alternativa. Os suportes cerâmicos foram produzidos por prensagem e sinterizados entre 1000 e $1200^{\circ} \mathrm{C}$. A influência da incorporação do resíduo de lama de papel nas propriedades físicas e microestrutura sinterizada foi investigada. Os resultados indicaram que o resíduo de lama de papel atua como um agente formador de poro. Os suportes cerâmicos produzidos apresentaram massa específica aparente de 1,16 a $2,01 \mathrm{~g} / \mathrm{cm}^{3}$, porosidade aparente de $14,6 \%$ a $46,7 \%$ e tensão de ruptura à flexão de 15,4 a 39,9 MPa. Análise microestrutural indicou que os suportes cerâmicos apresentaram estrutura morfológica altamente porosa. Tais resultados indicaram que suportes cerâmicos contendo até $30 \%$ em massa de resíduo de lama de papel têm potencial para serem empregados na fabricação de membranas de filtração.

Palavras-chaves: suporte cerâmico, resíduo de lama de papel, valorização, propriedades, microestrutura.
\end{abstract}

\begin{abstract}
The paper industry generates a huge volume of paper sludge waste. In this study, a new porous ceramic support using paper sludge waste as an alternative raw material was developed. The ceramic supports were produced by pressing and sintered between 1000 and $1200{ }^{\circ} \mathrm{C}$. The influence of the incorporation of the paper sludge waste on the physical properties and sintered microstructure was investigated. The results indicated that the paper sludge waste acts as a pore-forming agent. The produced ceramic supports showed an apparent specific mass of 1.16 to $2.01 \mathrm{~g} / \mathrm{cm}^{3}$, apparent porosity of $14.6 \%$ to $46.7 \%$, and flexural strength of 15.4 to 39.9 MPa. Microstructural analysis indicated that the ceramic supports had a highly porous morphological structure. Such results indicated that porous ceramic supports containing up to $30 \mathrm{wt} \%$ of paper sludge waste have the potential to be employed in the manufacture of filtration membranes.
\end{abstract}

Keywords: ceramic support, paper sludge waste, valorization, properties, microstructure.

\section{INTRODUÇÃO}

$\mathrm{Na}$ atualidade existe um interesse cada vez maior no reuso e valorização de resíduos poluentes como matérias-primas alternativas e renováveis aplicadas no desenvolvimento de materiais cerâmicos. Tal fato se deve principalmente à possibilidade de matérias-primas tradicionais serem substituídas parcial ou totalmente nas formulações cerâmicas por resíduos poluentes, que contribui para preservação das fontes de matérias-primas naturais com consideráveis benefícios econômicos e ambientais. O Brasil detém uma expressiva indústria de produção de papel. Em 2018, por exemplo, a produção brasileira de papel foi de 10,443 milhões de toneladas [1]. Tal volume de produção de papel gera riqueza e milhares de empregos diretos e indiretos. Por outro lado, a fabricação industrial de papel também

*bou_issa@hotmail.com

Dhttps://orcid.org/0000-0002-8718-7562 gera uma quantidade significativa de resíduo poluente na forma de lama, que é o produto final do processo após o tratamento de águas residuais em estação de tratamento de efluente [2-4]. Este resíduo apresenta-se na forma de uma lama de papel fibrosa de coloração acinzentada, a qual constitui uma mistura compósita formada principalmente de fibras de celulose, caulim, calcita, substâncias químicas usadas no tratamento e água [3, 4]. Do ponto de vista de potencial poluidor, é classificado de acordo com a norma ABNT NBR 10004 como um resíduo não perigoso, mas não inerte (classe IIA) [5]. Em geral a indústria do papel descarta este resíduo principalmente em aterro sanitário que apresenta custo elevado, além de ser problemático em termos de sustentabilidade ambiental $[4,6]$. Esta situação reforça a necessidade na busca de novas alternativas tecnológicas e viáveis para o descarte final sustentável deste abundante resíduo poluente.

As membranas cerâmicas são largamente empregadas em processos de microfiltração e ultrafiltração com largo 
campo de aplicação em processos industriais [7-10]. $\mathrm{O}$ suporte poroso é considerado parte fundamental da membrana cerâmica, pois é o responsável pela resistência mecânica e transporte de fluxo [11]. Os suportes cerâmicos comerciais são em regra caros devido ao alto custo das matérias-primas sintéticas usadas como, por exemplo, alumina, cordierita, óxido de titânio e mulita, além da alta temperatura de sinterização empregada $[9,11,12]$. Por este motivo, nos últimos anos têm sido estimuladas pesquisas voltadas para o desenvolvimento de novos suportes cerâmicos porosos usando matérias-primas convencionais baratas tais como argilas e caulins $[8,9,12,13]$. Verifica-se também que a literatura disponível é escassa em relação ao reuso e valorização de resíduos poluentes no processamento de suporte poroso de membrana cerâmica $[13,14]$. Em particular, o uso de resíduo de lama proveniente da indústria do papel ainda não tem sido investigado na produção de suporte cerâmico poroso de baixo custo para emprego em membrana. O objetivo principal deste trabalho é o desenvolvimento de um novo suporte cerâmico poroso de baixo custo para potencial aplicação em membrana cerâmica usando o resíduo de lama produzido na indústria de papel como um agente formador de poro.

\section{MATERIAIS E MÉTODOS}

As matérias-primas de partida utilizadas para processamento de suporte cerâmico poroso foram caulim comercial (Armil Mineração do Nordeste, Brasil) e resíduo de lama de papel fornecido pela Copapa (Rio de Janeiro, Brasil), que fabrica papel tissue (papéis usados como lenços, guardanapos, papel higiênico, etc.). O caulim foi fornecido na granulometria $<325$ mesh $(<45 \mu \mathrm{m}$ ASTM). O resíduo lama de papel coletado na forma in natura foi submetido a processo de secagem, desagregado e passado na peneira de 100 mesh $(<149 \mu \mathrm{m}$ ASTM). Após o beneficiamento foram estabelecidas as composições das massas cerâmicas, conforme mostrado na Tabela I. A massa cerâmica RB1 correspondeu à massa cerâmica de referência isenta de resíduo de lama de papel (isto é, 100\% de caulim).

As análises químicas das matérias-primas foram realizadas por combinação das técnicas de espectrometria de fluorescência de raios $X$ e espectrometria de absorção atômica. A perda ao fogo (PF) foi determinada a partir da

Tabela I - Composição das formulações cerâmicas usadas (\% em massa).

[Table I - Composition of the ceramic formulations used (mass \%).]

\begin{tabular}{ccc}
\hline Formulação & Caulim & $\begin{array}{c}\text { Resíduo de lama } \\
\text { de papel }\end{array}$ \\
\hline RB1 & 100 & 0 \\
RB2 & 90 & 10 \\
RB3 & 80 & 20 \\
RB4 & 70 & 30 \\
\hline
\end{tabular}

expressão $\mathrm{PF}(\%)=[(\mathrm{Ms}-\mathrm{Mc}) / \mathrm{Ms}] .100$, onde Ms é a massa da amostra seca (g) a $110^{\circ} \mathrm{C}$ e Mc é a massa da amostra calcinada (g) a $1000^{\circ} \mathrm{C}$ por $2 \mathrm{~h}$. A morfologia das partículas das matérias-primas foi observada por microscopia eletrônica de varredura (MEV) via imagens de elétrons secundários (Shimadzu, SSX-550). As análises térmicas (análise térmica diferencial, ATD, e análise termogravimétrica, ATG) das matérias-primas e massas cerâmicas foram realizadas em um analisador simultâneo ATG-ATD (Netzsch, STA 409E) da temperatura ambiente até $1100{ }^{\circ} \mathrm{C}$ com taxa de aquecimento de $10{ }^{\circ} \mathrm{C} / \mathrm{min}$.

As massas cerâmicas, com as proporções de caulim e resíduo de lama de papel (Tabela I) foram misturadas e homogeneizadas usando um misturador cilíndrico de laboratório durante $30 \mathrm{~min}$. Após mistura, as massas cerâmicas foram umedecidas com água (7\% em massa). Os suportes cerâmicos foram preparados por prensagem uniaxial em uma prensa hidráulica (Schwing Siwa, PHMA) usando pressão de compactação de aproximadamente 60 MPa e matriz de aço cilíndrica (diâmetro de $25 \mathrm{~mm}$ ). Os suportes cerâmicos compactados foram secados a $110{ }^{\circ} \mathrm{C}$ por $24 \mathrm{~h}$ e depois sinterizados em um forno mufla (Nova Instruments, NI1384) em atmosfera oxidante em patamar de $1000,1050,1100,1150$ e $1200{ }^{\circ} \mathrm{C}$ por $2 \mathrm{~h}$.

Os suportes cerâmicos preparados foram caracterizados em termos de absorção de água (AA), massa específica aparente (MEA), porosidade aparente (PA), retração linear, perda de massa, resistência mecânica e análise microestrutural. AA, PA e MEA foram determinadas de acordo com a norma ASTM C373. A retração linear foi determinada a partir das medidas do diâmetro das amostras cilíndricas após secagem e sinterização. A perda de massa das amostras foi determinada a partir das medidas de massa das amostras após secagem e sinterização usando uma balança analítica de precisão $\pm 0,01 \mathrm{~g}$. Devido à geometria das amostras sinterizadas (disco), a tensão de ruptura à flexão $\left(\sigma_{\mathrm{f}}\right)$ foi determinada a partir da expressão $\sigma_{\mathrm{f}}=2,7 . \sigma_{\mathrm{t}}(\mathrm{MPa})$ [9], onde $\sigma_{\mathrm{t}}=2 . \mathrm{P} /(\pi . \mathrm{d} . \mathrm{h})$ é a resistência à tração determinada pelo método de compressão diametral (P é a carga de ruptura, $\mathrm{d}$ é o diâmetro da amostra e h é a espessura da amostra). A carga de ruptura $(\mathrm{P})$ foi determinada usando uma máquina de ensaios universal (Instron, mod. 5582) com velocidade de carregamento de $0,5 \mathrm{~mm} / \mathrm{min}$. A microestrutura sinterizada foi avaliada por microscopia eletrônica de varredura via imagens de elétrons retroespalhados, após metalização com uma fina camada de paládio.

\section{RESULTADOS E DISCUSSÃO}

A Tabela II apresenta as composições químicas do caulim e do resíduo de lama de papel em termos de óxidos constituintes mais a perda ao fogo. Como esperado, o caulim usado foi composto essencialmente de $\mathrm{SiO}_{2}(46,92 \%$ em massa), $\mathrm{Al}_{2} \mathrm{O}_{3}(38,94 \%$ em massa) e pequenas quantidades de impurezas (óxidos de $\mathrm{Ca}, \mathrm{Mg}, \mathrm{Fe}, \mathrm{K}, \mathrm{Na}, \mathrm{Mn}$, Ti e P). $\mathrm{O}$ caulim apresentou razão $\mathrm{SiO}_{2} / \mathrm{Al}_{2} \mathrm{O}_{3}=1,21$. Este resultado indicou que o caulim foi constituído predominantemente 
pelo argilomineral caulinita [15]. De fato, a perda ao fogo do caulim foi de 12,88\% em massa, que foi próxima do valor teórico da caulinita $(13,95 \%)$. Os resultados da Tabela II também mostram que o resíduo de lama de papel foi principalmente composto de $\mathrm{CaO}(25,17 \%$ em massa) e quantidades menores de $\mathrm{SiO}_{2}\left(4,38 \%\right.$ em massa) e $\mathrm{Al}_{2} \mathrm{O}_{3}$ (4,35\% em massa). Tais resultados foram em acordo com dados de composição química do resíduo de lama de papel reportados na literatura [5]. Em particular, a alta quantidade de $\mathrm{CaO}$ se deve fundamentalmente à presença de material carbonáceo na forma de calcita $\left(\mathrm{CaCO}_{3}\right)$. Os componentes $\mathrm{SiO}_{2}$ e $\mathrm{Al}_{2} \mathrm{O}_{3}$ estavam na forma combinada formando a estrutura da caulinita, o que indicou que o resíduo de lama de papel continha caulim [4]. Constatou-se ainda que o resíduo de lama de papel apresentou alta perda ao fogo $(65,23 \% \mathrm{em}$ massa), associada principalmente à combustão de fibra de celulose e decomposição de calcita [4]. Isto significou que o resíduo de lama de papel por apresentar alta perda ao fogo pode desempenhar a função de um agente formador de poro. Do ponto de vista de processamento de um suporte cerâmico poroso, isto é positivo, em princípio.

Os aspectos morfológicos das partículas de caulim e

Tabela II - Composição química das matérias-primas (\% em massa).

[Table II - Chemical composition of the raw materials (mass \%).]

\begin{tabular}{ccc}
\hline Óxido & Caulim & $\begin{array}{c}\text { Resíduo de lama } \\
\text { de papel }\end{array}$ \\
\hline $\mathrm{SiO}_{2}$ & 46,92 & 4,38 \\
$\mathrm{Al}_{2} \mathrm{O}_{3}$ & 38,94 & 4,35 \\
$\mathrm{CaO}$ & 0,05 & 25,17 \\
$\mathrm{MgO}$ & 0,05 & 0,25 \\
$\mathrm{Fe}_{2} \mathrm{O}_{3}$ & 0,27 & 0,28 \\
$\mathrm{~K}_{2} \mathrm{O}$ & 0,64 & 0,06 \\
$\mathrm{Na}_{2} \mathrm{O}$ & 0,06 & 0,05 \\
$\mathrm{MnO}$ & 0,05 & 0,05 \\
$\mathrm{TiO}_{2}$ & 0,05 & 0,09 \\
$\mathrm{P}_{2} \mathrm{O}_{5}$ & 0,09 & 0,09 \\
Perda ao fogo & 12,88 & 65,23 \\
\hline
\end{tabular}

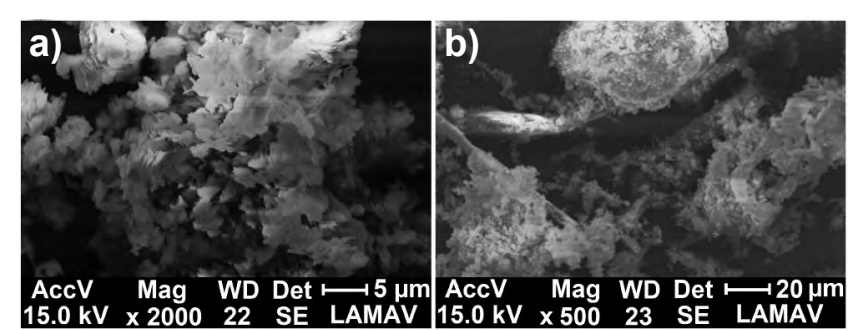

Figura 1: Micrografias de MEV: a) caulim; e b) resíduo de lama de papel.

[Figure 1: SEM micrographs: a) kaolin; and b) paper sludge waste.] resíduo de lama de papel podem ser observados na Fig. 1. O pó de caulim (Fig. 1a) foi composto essencialmente de partículas com morfologia em forma de placas. Tais placas são típicas do argilomineral caulinita que é o constituinte majoritário de caulins comerciais. A amostra de resíduo de lama de papel no estado seco (Fig. 1b) foi composta por aglomerados com morfologia irregular e textura altamente porosa. Tais aglomerados são constituídos principalmente de misturas de fibra de celulose, caulinita e calcita.

A Fig. 2 apresenta os resultados das análises térmicas (ATD/ATG) das matérias-primas e formulações cerâmicas estudadas. O comportamento térmico da amostra de caulim (Fig. 2a) pode ser descrito como: i) um pequeno evento endotérmico ocorreu entre $\sim 25$ e $200{ }^{\circ} \mathrm{C}$ relacionado à liberação de água fisicamente adsorvida sobre a superfície das partículas, com perda de massa de $0,63 \%$; ii) um expressivo evento endotérmico a $555,8{ }^{\circ} \mathrm{C}$ relacionado à desidroxilação das partículas de caulinita para formação da metacaulinita amorfa, com perda de massa de 10,54\%; e iii) um evento exotérmico a $1002,0{ }^{\circ} \mathrm{C}$ relacionado à decomposição da metacaulinita e concomitante formação de novas fases cristalinas, como estrutura espinélio (Al-Si) e/ ou a nucleação de mulita primária [16]. A perda de massa total obtida da curva ATG de $11,17 \%$ foi próxima do valor da perda ao fogo de $12,88 \%$ (Tabela II). O comportamento térmico do resíduo de lama de papel (Fig. 2b) pode ser descrito como: i) um evento endotérmico entre 24,9 e $199,7{ }^{\circ} \mathrm{C}$ relacionado à liberação de água fisicamente adsorvida acompanhada de perda de massa de 3,94\%; ii) um evento exotérmico entre 199,7 e $390,0{ }^{\circ} \mathrm{C}$ relacionado à decomposição de celulose e hemicelulose (isto é, perda de material volátil leve) [17], com alta perda de massa de $35,31 \%$; iii) um evento exotérmico entre 390,0 e $639,2{ }^{\circ} \mathrm{C}$ relacionado à decomposição de lignina (isto é, perda de material volátil mais pesado) [17], com perda de massa de $10,55 \%$. Ressalta-se que nesta faixa de temperatura, devido à presença de caulim no resíduo de lama de papel, o evento endotérmico relacionado à desidroxilação da caulinita provavelmente foi sobreposto; e iv) um evento endotérmico entre 639,2 e 889,1 ${ }^{\circ} \mathrm{C}$ relacionado à decomposição da calcita acompanhado de perda de massa de 17,90\%. Observou-se também que a perda de massa total do resíduo de lama de papel obtida da curva ATG foi cerca de $67,70 \%$, que foi em acordo com o valor da perda ao fogo de 65,23\% (Tabela II). Os comportamentos térmicos das formulações RB2 (Fig. 2c) e RB4 (Fig. 2d) foram em acordo com aqueles das matériasprimas individuais. Além disso, ambas as formulações apresentaram um evento exotérmico em aproximadamente $1000{ }^{\circ} \mathrm{C}$, o qual pode ser provavelmente atribuído à formação de fases de silicato e aluminossilicato de cálcio [4, 18]. As perdas de massas totais das formulações RB2 e RB4 foram $17,67 \%$ e $25,98 \%$, respectivamente.

As Figs. 3 e 4 mostram micrografias da superfície de fratura dos suportes cerâmicos das formulações RB1 e RB4, respectivamente, obtidas por microscopia eletrônica de varredura via imagens de elétrons retroespalhados. Tais micrografias mostraram a sequência típica do 

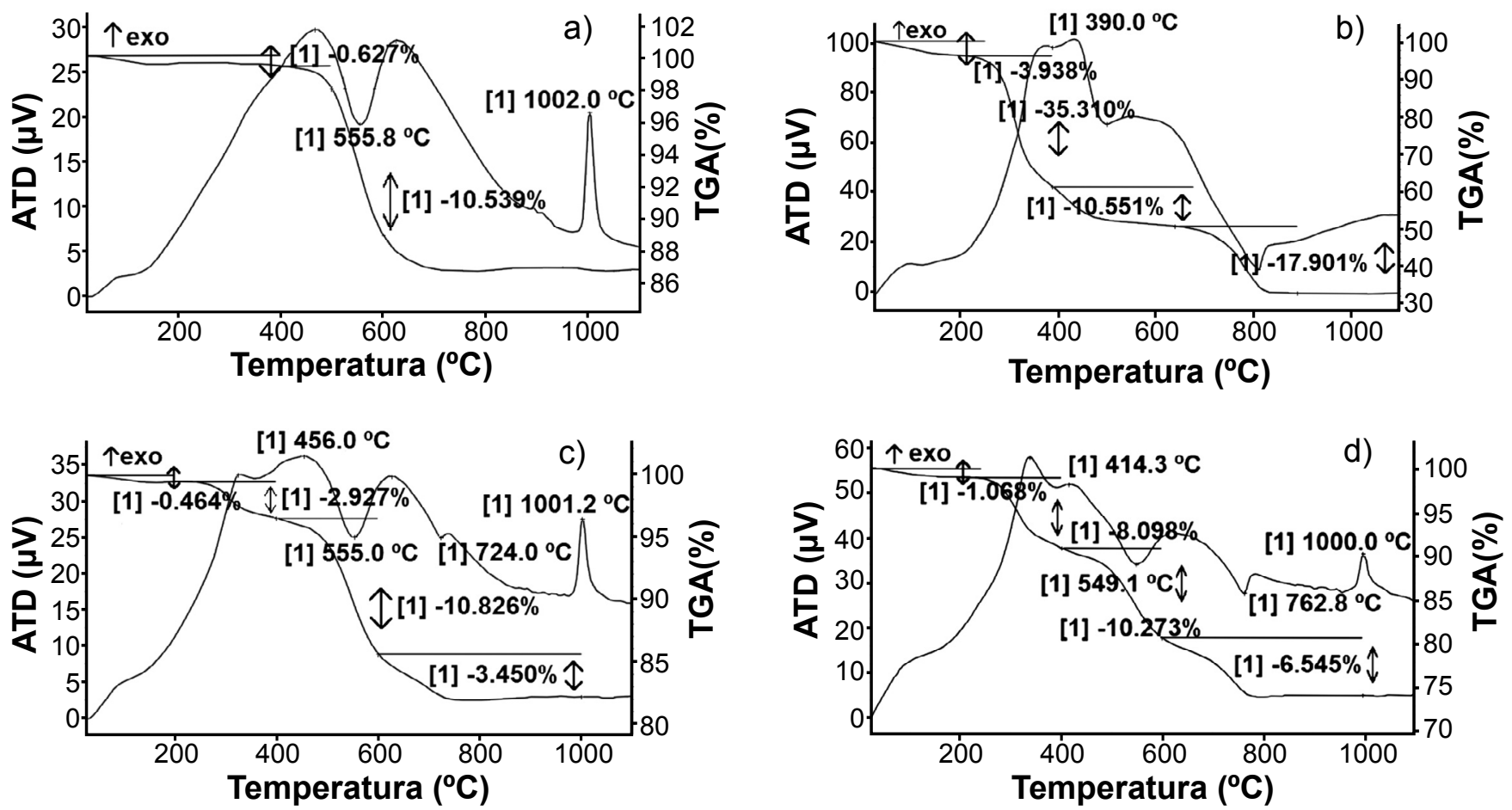

Figura 2: Curvas de ATD/ATG de: a) caulim; b) resíduo de lama de papel; c) formulação RB2; e d) formulação RB4. [Figure 2: DTA/TG curves of: a) kaolin; b) paper sludge waste; c) RB2 formulation; and d) RB4 formulation.]
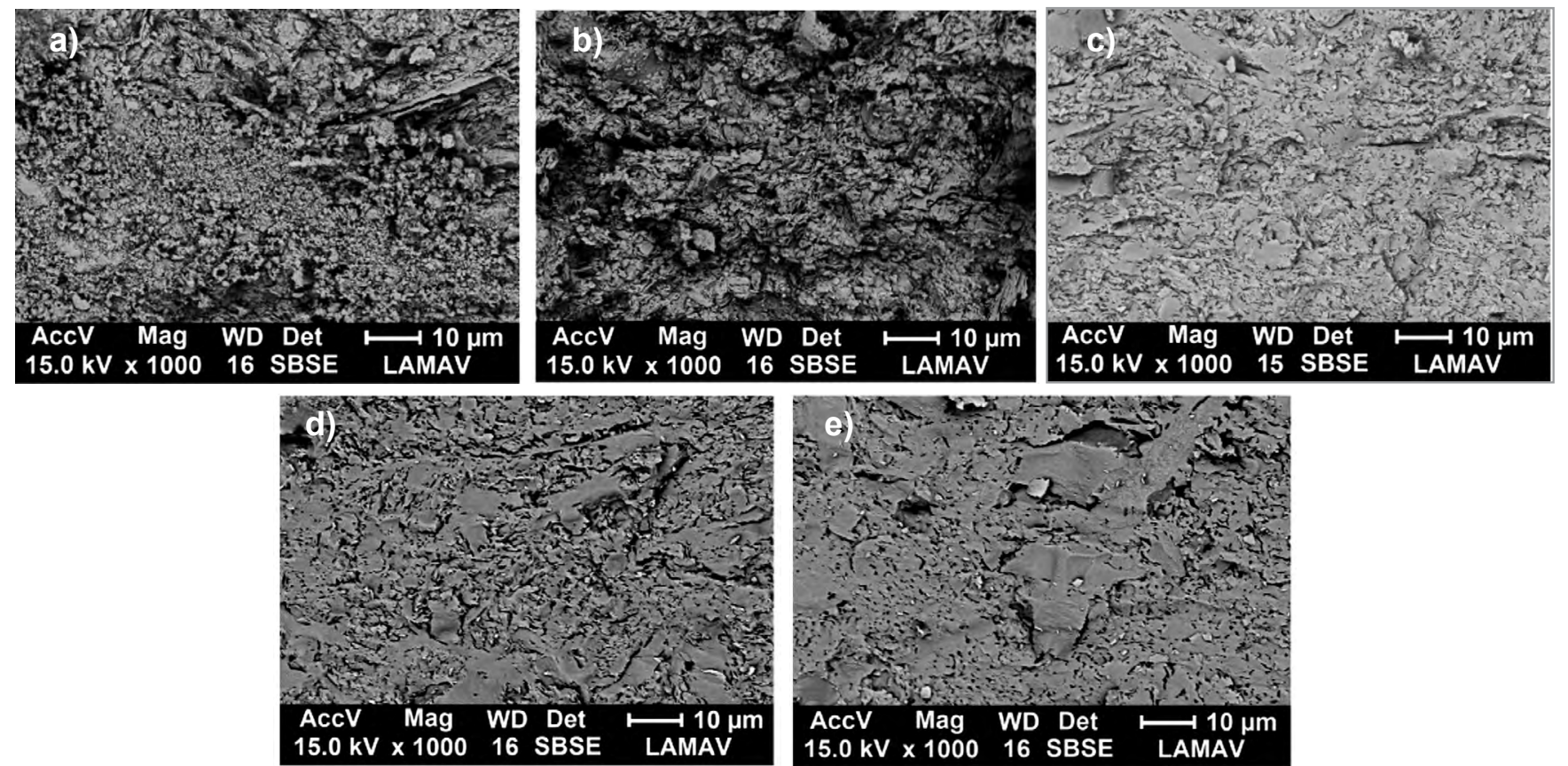

Figura 3: Micrografias de MEV das superfícies de fratura da formulação RB1 em diferentes temperaturas de sinterização: a) $1000{ }^{\circ} \mathrm{C}$; b) $1050{ }^{\circ} \mathrm{C}$; c) $1100^{\circ} \mathrm{C}$; d) $1150{ }^{\circ} \mathrm{C}$; e e) $1200^{\circ} \mathrm{C}$.

[Figure 3: SEM micrographs of the fracture surfaces of the $\mathrm{RB} 1$ formulation at different sintering temperatures: a) $1000{ }^{\circ} \mathrm{C}$; b) $1050{ }^{\circ} \mathrm{C}$; c) $1100{ }^{\circ} \mathrm{C}$; d) $1150{ }^{\circ} \mathrm{C}$; and e) $1200{ }^{\circ} \mathrm{C}$.]

comportamento da microestrutura dos suportes cerâmicos com o aumento da temperatura de sinterização. Como esperado, o efeito da temperatura de sinterização foi o de aumentar o grau de sinterização com concomitante redução da porosidade aberta em todos os suportes cerâmicos. Por outro lado, a análise comparativa entre as superfícies de fratura das formulações RB1 (Fig. 3) e RB4 (Fig. 4) indicou claramente que a incorporação de resíduo de lama de papel atuou como um agente formador de poros, o qual resultou em estruturas sinterizadas altamente porosas (Fig. 4). De fato, o suporte cerâmico produzido com o resíduo de lama de papel apresentou maior quantidade de poros 

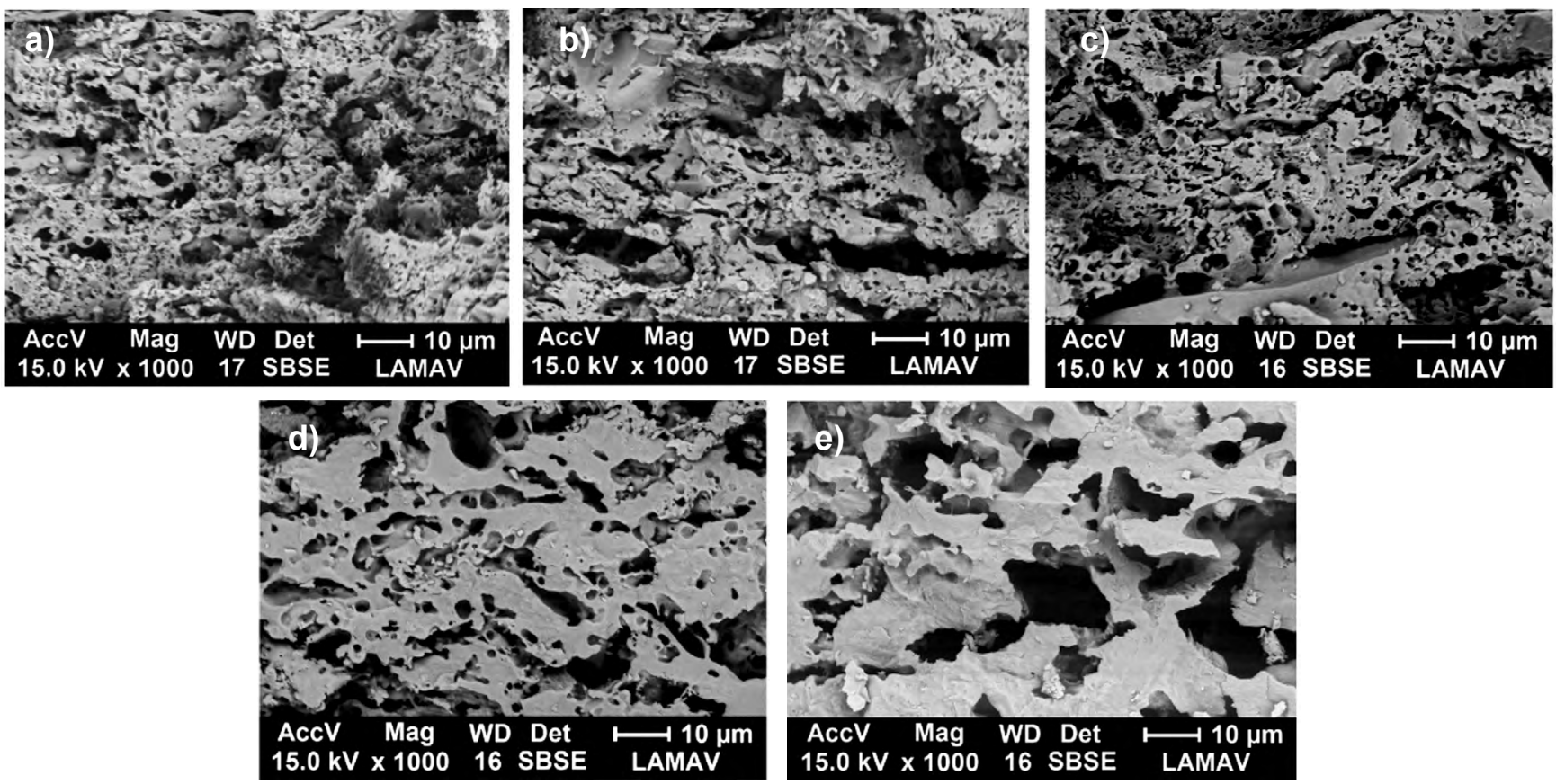

Figura 4: Micrografias de MEV das superfícies de fratura da formulação RB4 em diferentes temperaturas de sinterização: a) $1000{ }^{\circ} \mathrm{C}$; b) $1050{ }^{\circ} \mathrm{C}$; c) $1100^{\circ} \mathrm{C}$; d) $1150{ }^{\circ} \mathrm{C}$; e e) $1200{ }^{\circ} \mathrm{C}$.

[Figure 4: SEM micrographs of the fracture surfaces of the RB4 formulation at different sintering temperatures: a) $1000{ }^{\circ} \mathrm{C}$; b) $1050{ }^{\circ} \mathrm{C}$; c) $1100{ }^{\circ} \mathrm{C}$; d) $1150{ }^{\circ} \mathrm{C}$; and e) $\left.1200{ }^{\circ} \mathrm{C}.\right]$

observáveis de diferentes tamanhos e bem distribuídos. Isto foi em acordo com a destruição térmica do resíduo de lama de papel durante o processo de sinterização, conforme os comportamentos térmicos observados na Fig. 2. A inspeção das superfícies de fratura constatou ainda ausência de trincas e defeitos superficiais nos suportes cerâmicos.

A evolução das propriedades físicas dos suportes cerâmicos em função da temperatura de sinterização e quantidade de resíduo de lama de papel é mostrada na Fig. 5. A correlação entre as propriedades físicas foi estabelecida. A Fig. 5a mostra o comportamento da retração linear (variação do diâmetro) dos suportes cerâmicos em função da temperatura de sinterização e quantidade de resíduo de lama de papel adicionado. A retração linear é fundamentalmente associada ao grau de sinterização da amostra. O efeito da temperatura de sinterização foi aumentar a retração linear dos suportes. Tal efeito está relacionado à maior sinterabilidade que promove uma aproximação entre as partículas, o qual resulta no aumento da retração. Deve-se notar, no entanto, que a adição de $30 \%$ em massa de resíduo de lama de papel (formulação RB4) praticamente não alterou a retração linear dos suportes na faixa de temperatura de sinterização empregada. Pode-se observar também na Fig. 5a que o comportamento de sinterização dos suportes foi influenciado pela quantidade de resíduo adicionado. Notou-se que acima de $1000^{\circ} \mathrm{C}$ ocorreu uma tendência de menor valor de retração linear com a incorporação do resíduo. Este comportamento se deve basicamente à composição do resíduo de lama de papel que continha quantidades apreciáveis de compostos como fibra de celulose e carbonato de cálcio. Tais compostos se decompuseram durante o processo de sinterização com concomitante liberação de voláteis para fora da estrutura do suporte cerâmico. A perda de massa dos suportes cerâmicos durante o processo de sinterização é mostrada na Fig. 5b. Como esperado, os suportes cerâmicos contendo resíduo de lama de papel apresentaram altos valores de perda de massa $(20,7 \%$ a 36,2\%). Os suportes cerâmicos apresentaram um intenso processo de transferência de massa, no qual ocorreram reações químicas complexas associadas ao caulim (desidroxilação da caulinita: $\left.\mathrm{Al}_{2} \mathrm{O}_{3} \cdot 2 \mathrm{SiO}_{2} \cdot 2 \mathrm{H}_{2} \mathrm{O} \rightarrow \mathrm{Al}_{2} \mathrm{O}_{3} \cdot 2 \mathrm{SiO}_{2}+\mathrm{H}_{2} \mathrm{O} \uparrow\right)$ e resíduo de lama de papel (combustão da fibra de celulose e decomposição da calcita: $\mathrm{CaCO}_{3} \rightarrow \mathrm{CaO}+\mathrm{CO}_{2} \uparrow$ ). Este resultado foi em acordo com os resultados das análises térmicas (ATD/ATG) mostrados na Fig. 2. Observou-se também que em qualquer temperatura de sinterização o efeito do resíduo de lama de papel foi o de elevar substancialmente a perda de massa dos suportes cerâmicos. No entanto, para as formulações RB3 e RB4 queimadas a $1200{ }^{\circ} \mathrm{C}$ ocorreu um aumento súbito de perda de massa em relação a $1150{ }^{\circ} \mathrm{C}$. Não se encontrou uma explicação plausível para essa perda de massa, pois aparentemente as reações de perda de massa envolvidas foram aquelas descritas pelas curvas de ATG, de forma que é necessária mais investigação para elucidar tal elevação da perda de massa, a qual será objeto de trabalho futuro.

O comportamento da massa específica aparente dos suportes cerâmicos em função da temperatura de sinterização e quantidade de resíduo é mostrado na Fig. 5c. A massa específica aparente dos suportes cerâmicos sinterizados contendo resíduo de lama de papel foi na faixa de 1,16 a $2,01 \mathrm{~g} / \mathrm{cm}^{3}$. O comportamento de densificação 

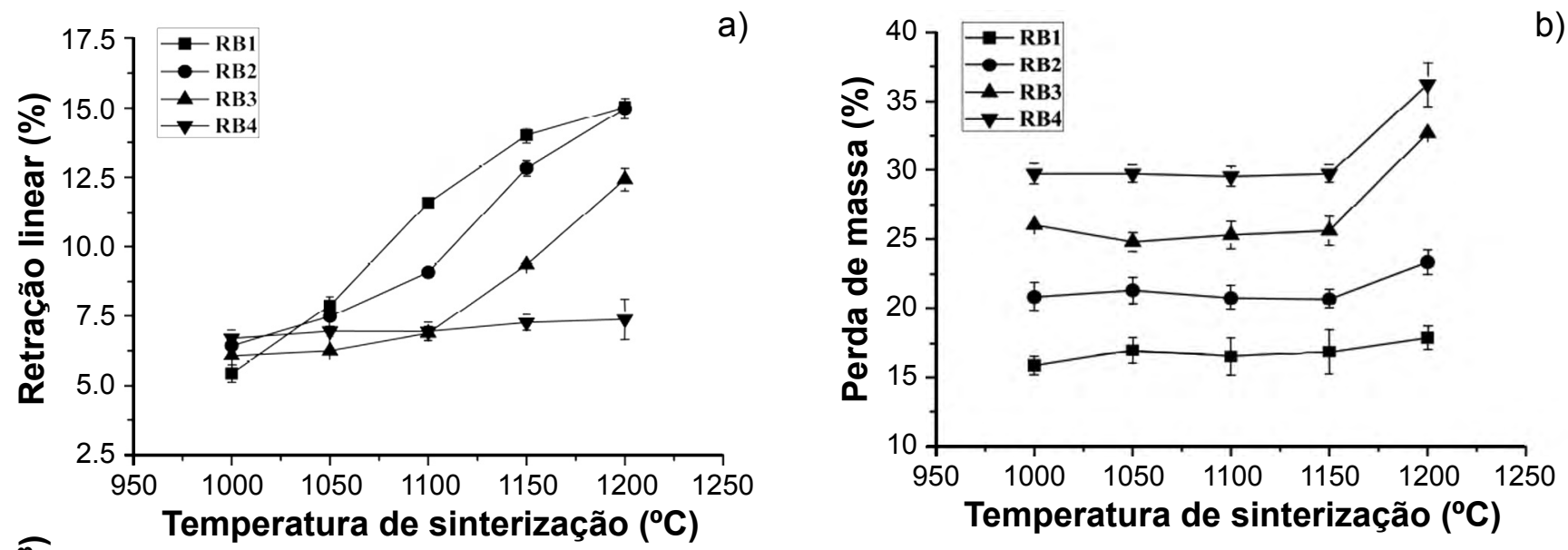

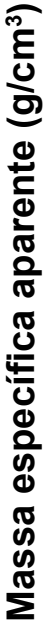
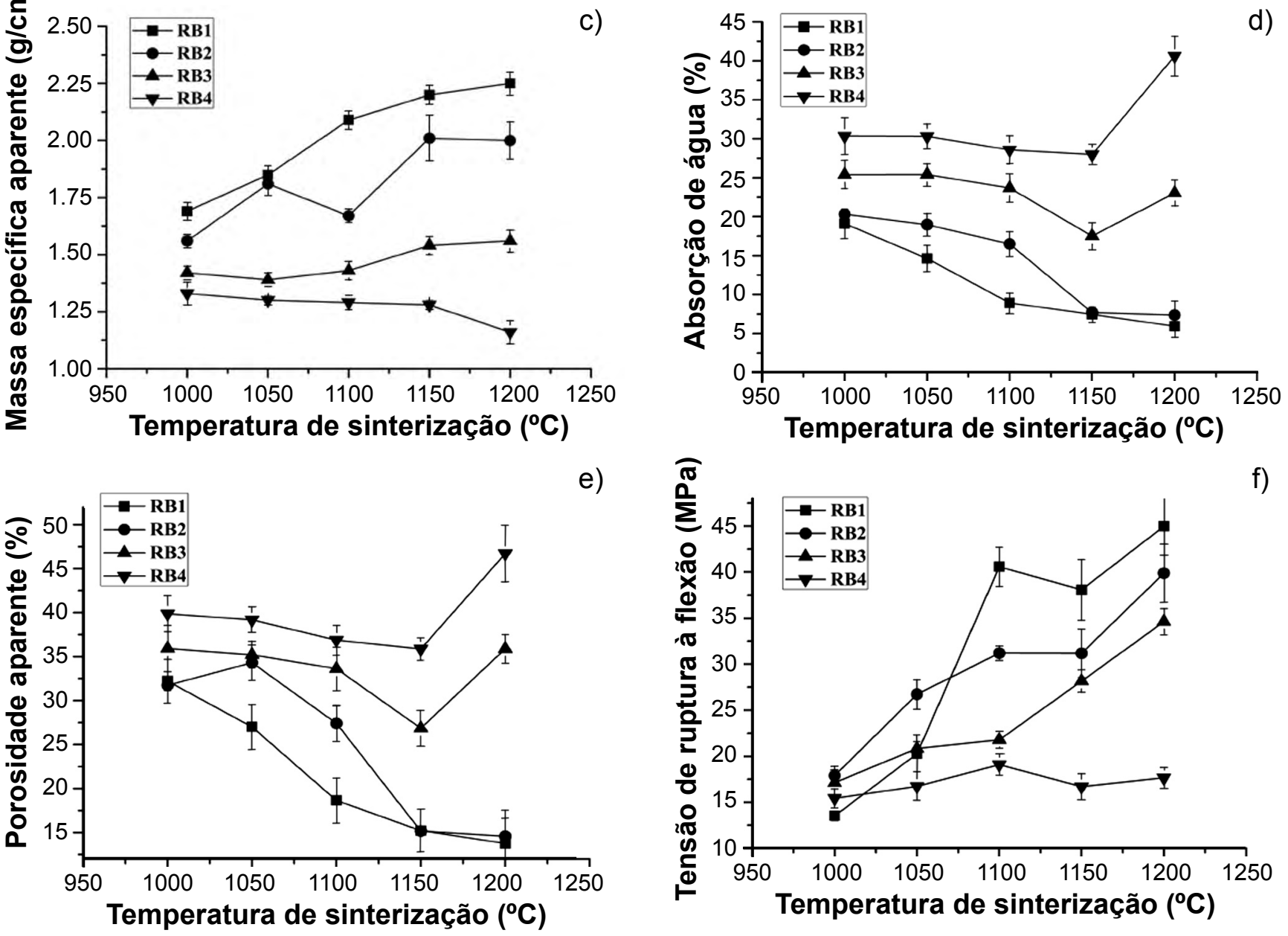

Figura 5: Resultados de retração linear (a), perda de massa (b), massa específica aparente (c), absorção de água (d), porosidade aparente (e) e tensão de ruptura a flexão (f) dos suportes cerâmicos.

[Figure 5: Results of linear shrinkage (a), mass loss (b), apparent specific mass (c), water absorption (d), apparent porosity (e), and flexural strength (f) of the ceramic supports.]

dos suportes cerâmicos foi associado a dois fatores opostos simultâneos influenciando a densificação, quais sejam: i) sinterização devido ao crescimento de pescoço interpartícula dominada principalmente por sinterização de estado sólido; e ii) desgaseificação relacionada à liberação de voláteis oriundos principalmente da combustão da fibra de celulose e decomposição de calcita. No entanto, a perda de massa oriunda da desgaseificação foi o parâmetro predominante na densificação dos suportes cerâmicos. De fato, em todas as temperaturas de sinterização a incorporação de maior quantidade de resíduo de lama de papel resultou em menor taxa de densificação, formação de porosidade e expansão 
da estrutura. Este comportamento foi consistente com as microestruturas (Fig. 4), retração linear (Fig. 5a) e perda de massa (Fig. 5b). A Fig. 5d mostra os valores de absorção de água dos suportes cerâmicos. Como esperado, a substituição do caulim com resíduo de lama de papel resultou em maior absorção de água para todas as temperaturas de sinterização. Este aumento de absorção de água foi essencialmente em linha com a composição do resíduo de lama de papel e perda de massa (Fig. 5b) que tendeu a originar porosidade aberta e retardar a densificação dos suportes cerâmicos.

A Fig. 5e mostra a evolução da porosidade aparente dos suportes cerâmicos a diferentes temperaturas de sinterização. Como esperado, os suportes cerâmicos incorporados com resíduo de lama de papel tenderam a apresentar maior porosidade do que aqueles isentos de resíduo. Tal efeito foi em acordo com a perda de massa (Fig. 5b), massa específica aparente (Fig. 5c) e absorção de água (Fig. 5d). Quanto maior foi a quantidade de resíduo de lama de papel incorporado, maior foi a quantidade de porosidade formada na estrutura do suporte cerâmico. Isto é interessante devido à formação de maior porosidade aumentar a permeabilidade do suporte cerâmico, que é de alto interesse para aplicação em membranas. O mecanismo de formação de porosidade neste novo suporte cerâmico foi intimamente relacionado aos processos de destruição térmica da fibra de celulose e calcita presentes no resíduo de lama de papel, que ocorreram em distintas regiões de temperatura durante a etapa de sinterização. Neste trabalho os suportes cerâmicos incorporados com resíduo de lama de papel apresentaram os seguintes valores de porosidade aparente conforme a formulação: RB2 14,6\% a 34,3\%; RB3 26,9\% a 35,9\%; e RB4 $35,9 \%$ a $46,7 \%$. Tais resultados indicaram que as formulações contendo resíduo de lama de papel apresentam potencial em termos de produção de suporte cerâmico poroso aplicado em membranas de filtração de baixo custo [19], principalmente a formulação RB4. A tensão de ruptura à flexão dos suportes cerâmicos é mostrada na Fig. 5 f. $\mathrm{O}$ comportamento mecânico apresentou boa correlação com todas as outras propriedades estudadas e microestrutura sinterizada. Observou-se que a incorporação de maior quantidade de resíduo de lama de papel diminuiu a resistência mecânica do suporte cerâmico. Isto foi consequência direta do aumento da porosidade, como mostrado na Fig. 5e. As formulações contendo resíduo de lama de papel apresentaram os seguintes valores de tensão de ruptura à flexão conforme a formulação: RB2 17,9 a 39,9 MPa; RB3 17,1 a 34,6 MPa; e RB4 15,4 a 19,1 MPa, de forma que os suportes cerâmicos apresentaram resistência mecânica adequada para aplicação em membranas de filtração [20].

\section{CONCLUSÕES}

O resíduo de lama de papel gerado na indústria de papel pode ser usado como uma matéria-prima renovável barata que apresenta potencial para substituir parcialmente o caulim natural em formulações para fabricação de suporte cerâmico poroso. O resíduo de lama de papel foi composto principalmente de carbonato de cálcio na forma de calcita e fibras de celulose, cuja perda de massa total obtida da curva ATG foi de $67,70 \%$. A incorporação do resíduo de lama de papel causou importantes mudanças nas propriedades técnicas (retração linear, massa específica aparente, absorção de água, porosidade aparente e tensão de ruptura à flexão) e microestrutura sinterizada dos suportes cerâmicos. $\mathrm{O}$ resíduo de lama de papel atuou positivamente como um agente formador de poros durante o processo de sinterização do suporte cerâmico. Os resultados também indicaram que suportes cerâmicos porosos contendo $30 \%$ em massa de resíduo de lama de papel têm potencial para serem usados em membranas de filtração. Esta se constitui uma alternativa tecnológica viável de reuso e valorização de resíduo poluente produzido na indústria de papel, atual e de grande importância econômica e ambiental.

\section{AGRADECIMENTOS}

Os autores agradecem ao CNPq (Processo 305928/20163) e FAPERJ (Processo E-26/ 203.013/2016) pelo apoio financeiro a este trabalho. Os autores também gostariam de agradecer à empresa COPAPA (Companhia Paduana de Papéis) pelo fornecimento do resíduo de lama de papel.

\section{REFERÊNCIAS}

[1] IBÁ, "Estatísticas da indústria brasileira de árvores", Boletim 57 (2019) 1.

[2] M. Sutcu, S. Akkurt, Ceram. Int. 35 (2009) 2625.

[3] M.C. Monte, E. Fuente, A. Blanco, C. Negro, Waste Manag. 29 (2009) 293.

[4] J.A. Cusidó, L.V. Cremades, S. Soriano, M. Devant, Appl. Clay Sci. 108 (2015) 191.

[5] R.M. Pinheiro, "Reciclagem de lodo primário da estação de tratamento de efluentes da indústria de papel em cerâmica argilosa", Diss. Mestr., UENF, Campos dos Goytacazes (2008).

[6] S.K. Ding, S. Kulkarni, V. Kumar, P. Vashistha, J. Clean. Prod. 204 (2018) 321.

[7] J.M. Benito, A. Conesa, F. Rubio, M.A. Rodriguez, J. Eur. Ceram. Soc. 25 (2005) 1895.

[8] S. Sarker, S. Bamdyopadhyay, A. Larbot, S. Cerneaux, J. Membr. Sci. 392-393 (2012) 130.

[9] A. Harabi, F. Zenikheri, B. Boudaira, F. Bouzeraba, A. Guechi, L. Foughali, J. Eur. Ceram. Soc. 34 (2014) 1329.

[10] B. Das, B. Chakrabarty, P. Barkakati, Ceram. Int. 42 (2016) 14326.

[11] G. Chen, H. Qi, W. Xing, N. Xu, J. Membr. Sci. 318 (2008) 38.

[12] I. Hedfi, N. Hamdi, M.A. Rodriguez, E. Srasra, Ceram. Int. 42 (2016) 5089.

[13] V.J. Silva, M.F. Silva, W.P. Gonçalves, R.R. Menezes, G.A. Neves, H.L. Lira, L.N.L. Santana, Ceram. Int. 42 (2016) 15471.

[14] J. Liu, Y. Dong, X. Dong, S. Hampshire, L. Zhur, Z. Zhur, L. Li, J. Eur. Ceram. Soc. 36 (2016) 1059. 
[15] G.P. Souza, S.J.G. Sousa, L.A.H. Terrones, J.N.F. Holanda, Cerâmica 51, 320 (2005) 381.

[16] G.P. Souza, R. Sánchez, J.N.F. Holanda, J. Therm. Anal. Calor. 79 (2003) 293.

[17] M.R.C. Silva, A.S. Gurgel, S.L.F. Andersen, in Anais XI Congr. Bras. Eng. Quím. Inic. Cient., Campinas (2015).

[18] M.M. Jordam, M.B. Almendro-Candel, M. Romero,
J.M. Rincón, Appl. Clay Sci. 30 (2005) 219.

[19] R.C.O. Lima, H.L. Lira, G.A. Neves, M.C. Silva, S.D. Silva, Rev. Eletron. Mater. Process. 63 (2011) 163.

[20] N. Kouras, A. Harabi, F. Bouzerara, L. Fouguali, A. Policicchio, S. Stelitano, F. Galiano, A. Figoli, J. Eur. Ceram. Soc. 37 (2017) 3159.

(Rec. 10/05/2019, Rev. 09/08/2019, 09/10/2019, Ac. $01 / 11 / 2019)$ 